\title{
Fracture Failure Analysis for MQXFA Magnet Aluminum Shells
}

\author{
H. Pan $^{1}$, E. C. Anderssen ${ }^{1}$, G. Ambrosio ${ }^{3}$, D. W. Cheng ${ }^{1}$, P. Ferracin ${ }^{2}$, S. O. Prestemon ${ }^{1}$, E. T. Takala ${ }^{2}$, G. Vallone ${ }^{1}$
}

\begin{abstract}
The High-Luminosity LHC Accelerator Upgrade Project (HL-LHC AUP) is approaching the production phase of the US-contributed Q1 and Q3 Interaction Region Quadrupoles (MQXFA). The structures for the MQXFA prototypes were design and inspected by the US-LARP (LHC Accelerator Research Program), AUP developed criteria, which will be used for the pre-series structures. As the first two full-length prototypes with $4.2 \mathrm{~m}$ magnetic length, MQXFAP1 and MQXFAP2, were designed and assembled at Lawrence Berkeley National Laboratory (LBNL), and tested at Brookhaven National Laboratory (BNL). The end aluminum short shell of MQXFAP2 was fractured along the shell length during the test, and tests were stopped. Analytical and Finite Element analysis were performed in light of the graded procedure defined in the Structure Design Criteria to investigate the fracture failure for MQXFAP2.
\end{abstract}

In this paper, we report the fracture analysis of the current shell design, including the elasto-plastic simulations with submodel technique, and calculations with Linear Elastic Fracture Mechanics (LEFM). Test material properties are also presented. The results of this analysis explain why the end shell of MQXFAP2 failed, and suggest fillets on the end shell notches to meet the margin specified in the Structural Design Criteria.

Index Terms-Fracture analysis, HL-LHC AUP, Mechanical Analysis, Superconducting magnet

\section{INTRODUCTION}

$\mathrm{T}$ HE High-Luminosity Large Hadron Collider upgrade requires new quadrupoles, MQXF, to replace the present LHC inner triplet magnets [1]. The MQXFA magnet is the first prototype that has a $150 \mathrm{~mm}$ aperture and uses $\mathrm{Nb} 3 \mathrm{Sn}$ superconducting technology in a $4.2 \mathrm{~m}$ magnetic length structure. As same as the previous LARP HQ and MQXFS magnets [2], MQXFA magnet has the same cross section (Fig. 1 ), and relies on the pre-tension of the aluminum 7075-T6 shell, which is pre-loaded at room temperature [3, 4] with the bladder-and-key technology.

As prototypes of MQXF magnets, MQXFA magnet iterates three magnet-builds in the last two years --- MQXFAP1a, MQXFAP2, and MQXFAP1b, MQXFAP1a and MQXFAP2 have been tested at Brookhaven National Laboratory (BNL),

Manuscript received September 24, 2019. This work was supported by the U.S. Department of Energy, Office of Science, Office of High Energy Physics, through the US LHC Accelerator Upgrade Project (AUP), and by the High Luminosity LHC project at CERN.

H. Pan, E. C. Anderssen, S. O. Prestemon, D. W. Cheng, are with Lawrence Berkeley Laboratory (LBNL), Berkeley, CA, 94720 (email: hengpan@lbl.gov).

E. T. Takala, P. Ferracin, are with The European Organization for Nuclear Research (CERN), 1211 Meyrin, Switzerland.

G. Ambrosio is with the Fermi National Accelerator Laboratory (FNAL), Batavia, IL 80510 USA.

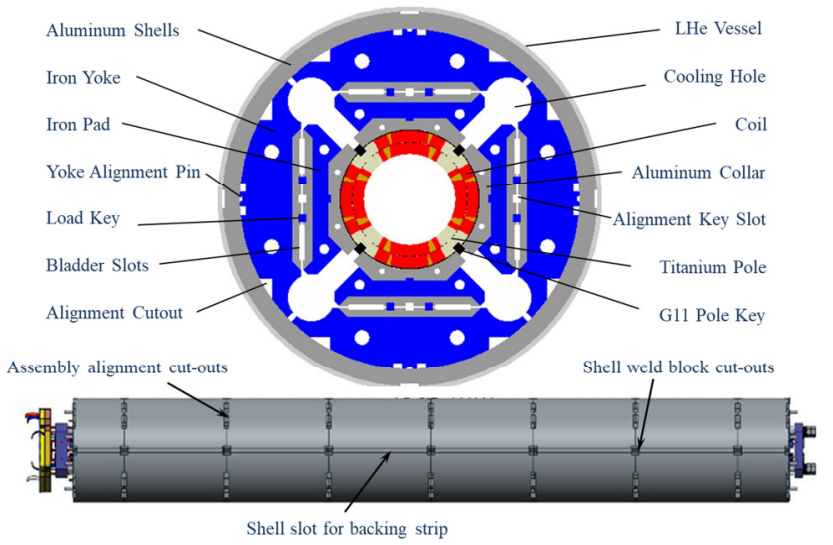

Fig. 1 Cross-sectional and longitudinal view of MQXFA magnet with original shell designs.

and MQXFAP1b was tested as the $1^{\text {st }}$ round and it's under improvements.

The cold test of MQXFAP2 was stopped by a notable unstable structure behavior, which was identified fracture failure on the end shell. Fracture analyses for MQXF magnets have been performed, and predicted the potential fracture failure with the original shell designs [5]. However, MQXFAP2 magnet has been assembled with the shells that be made before the analyses started.

In this paper, we describe the fracture failure on the MQXFAP2 end shell; try to explain the fracture mechanism under the load at $1.9 \mathrm{~K}$, and present the new fillet design on all of the cut-outs to prevent such failure with more than $20 \%$ safety margin as specified in the Structural Design Criteria [6].

\section{FRACTURE FAILURE IN MQXFAP2 SHELL}

The design of the shell-based support structure for MQXF magnet is to counteract nominal forces of $+2.47 /-3.48 \mathrm{MN} / \mathrm{m}$ (Fx/Fy) without overstressing the brittle Nb3Sn coils by tensioning the shells to a certain level at room temperature. The shells will achieve the final load level after cool-down to $1.9 \mathrm{~K}$ due to different thermal contractions of the components.

MQXFAP2 magnet was pre-loaded to the similar level of MQXFS1b, with about $35 \%$ shell force interception by the G11 pole keys. Fig. 2 shows the transfer function induced from the measured strain of MQXFAP2 and MQXFAP1 magnets. The plot shows the measured average stresses on the titanium pole and on shell after the room temperature loading and the cool-down. The colored rectangles represent the variation of the measurements across the four magnet quadrants.

As seen in Fig. 2, the average shell azimuthal stress of MQXFAP2 is about $152 \mathrm{MPa}$ after cool-down to $1.9 \mathrm{~K}$, which

This manuscript has been authored by Fermi Research Alliance, LLC under Contract No. DE-AC02-07CH11359 with the U.S. Department of Energy, Office of Science, Office of High Energy Physics. 


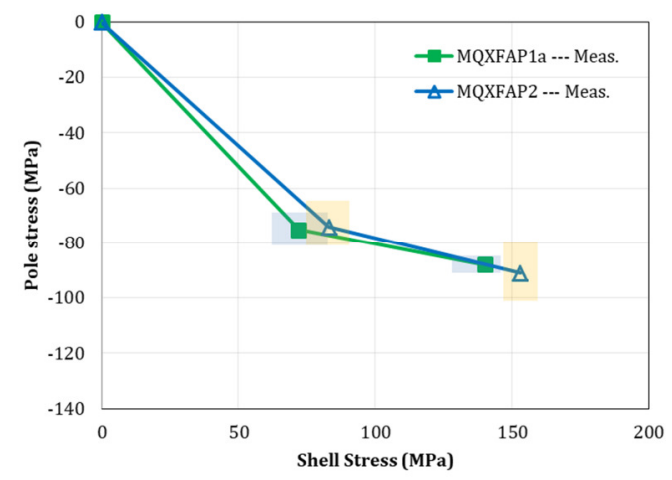

Fig. 2 Transfer function plot of the MQXFAP1 and AP2 magnets (colored blocks represent measurement errors of the strain gauges)

is $16 \mathrm{MPa}$ higher than that of MQXFAP1a. The shell stress of MQXFAP1b is small because of reduced the pole key interception.

The performance test of MQXFAP2 shows abnormal training behavior particularly on the RE (Return End), the test was stopped thereafter. Once the magnet was pulled out from the vertical test facility, a notable through crack and two more partial through cracks were observed on the end shell of the RE.
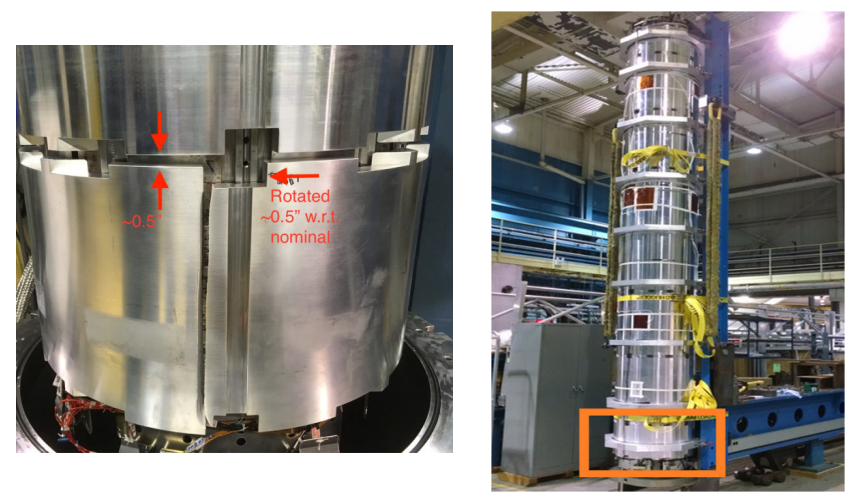

Fig. 3 The through crack on the fractured shell (left) and the broken shell's location in the vertical test facility (right, orange box).

As shown in Fig. 3 (left), a longitudinal crack was plainly evident in the RE end shell (located in the orange box of the right photo). The shell displaced by approximately $15 \mathrm{~mm}$
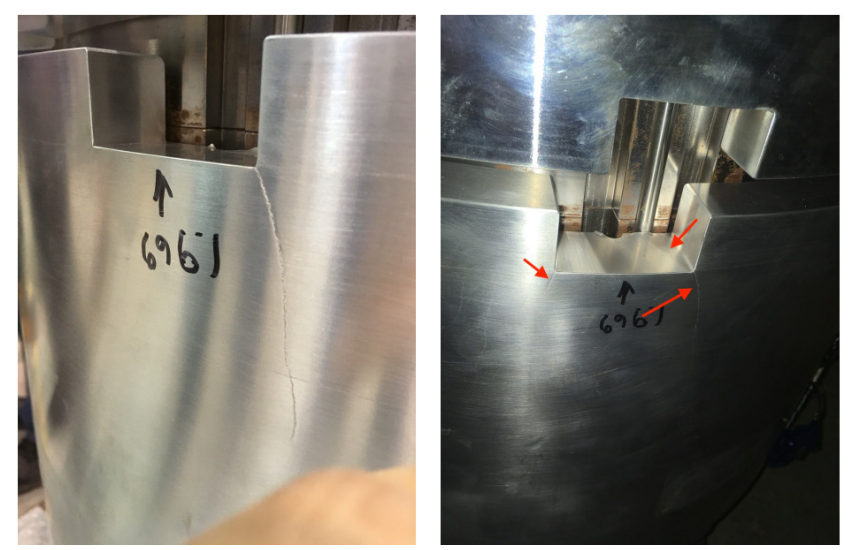

Fig. 4 The other two noticeable cracks on the broken shell: one long crack (left) and the small crack initiated from another corner (right). axially, and rotated also about $0.5^{\circ}$. The fractured surface appears rough, and no "fatigue-induced" cyclic rubbing appears present based on microscope checks.

The other welding block cutout of the "Top" side of the shell also exhibited initiation of fracture on both corners.(See Fig. 4). These cracks are visible emanating from the corners, also extending radially inward on the flat surface.

Subsequent examination of the material certs and inspection were conducted by LBNL. The results are listed in Table I.

TABLE I

SHELl MATERIAL INSPECTION RESULTS

\begin{tabular}{llcc}
\hline \hline Magnet & Material & $\begin{array}{c}\text { Ave. shell stress } \\
(\mathrm{MPa})\end{array}$ & Corner radii (mm) \\
\hline MQXFAP1 & Al 7075-T6 & 137 & $0.03-0.14$ \\
$\begin{array}{l}\text { MQXFAP2 } \\
\text { (End shells) }\end{array}$ & $\begin{array}{l}\text { Al 7075- } \\
\text { T652 }\end{array}$ & 152 & $\begin{array}{c}0.02 \text { (Broken shell), } \\
>0.75 \text { (LE shell) }\end{array}$ \\
$\begin{array}{l}\text { MQXFAP2 } \\
\text { (other shells) }\end{array}$ & Al 7075-T6 & 152 & $>0.75$ \\
\hline \hline
\end{tabular}

As reported in Table I, there are two non-conforming parameters of the fractured shell: (a) the material; and (b) the corner radii of the cut-outs. The shell material is chosen 7075T6 is to specifically minimize the residual stresses in the forged materials. In order to check the impact of different materials, fracture toughness tests of the samples from the fractured shell and conforming shells have been tested at $4.2 \mathrm{~K}$.

TABLE II

FRACTURE TOUGHNESS TEST RESULTS AT $4.2 \mathrm{~K}$

\begin{tabular}{|c|c|c|c|}
\hline Material & $\begin{array}{c}\text { Load } \\
\text { Direction }\end{array}$ & $\begin{array}{c}\text { Crack } \\
\text { direction }\end{array}$ & $\begin{array}{c}\mathrm{K}_{\mathrm{q}} \\
(\mathrm{MPa} \cdot \sqrt{\mathrm{m}})\end{array}$ \\
\hline \multirow{3}{*}{$\mathrm{Al} 7075-\mathrm{T} 6$} & $\mathrm{R}$ & $\mathrm{C}$ & 16.3 \\
\hline & $\mathrm{C}$ & $\mathrm{L}$ & 26.7 \\
\hline & $\mathrm{L}$ & $\mathrm{C}$ & 20.7 \\
\hline \multirow{7}{*}{ Al 7075-T652 } & $\mathrm{C}$ & $\mathrm{R}$ & 27.2 \\
\hline & $\mathrm{C}$ & $\mathrm{R}$ & 24 \\
\hline & $\mathrm{R}$ & $\mathrm{C}$ & 15.8 \\
\hline & $\mathrm{R}$ & $\mathrm{C}$ & 16.5 \\
\hline & $\mathrm{L}$ & $\mathrm{C}$ & 26.8 \\
\hline & $\mathrm{C}$ & $\mathrm{L}$ & 24.8 \\
\hline & $\mathrm{C}$ & $\mathrm{L}$ & 27.6 \\
\hline
\end{tabular}

Table II lists the test results at $4.2 \mathrm{~K}$ of each sample. Samples were prepared based on the orientations as defined in [7], the letters C, L and R represent circumferential, radial and longitudinal, respectively. In the case of MQXFAP2, the load direction is circumferential, and the crack is longitudinal. It's clearly that both materials are sensitive to directions; although the sample size is small, it's rational that the measured fracture toughness of both materials is close in $\mathrm{C}$ - $\mathrm{L}$ directions, which is above $24 \mathrm{MPa} \cdot \sqrt{\mathrm{m}}$. Although the measured fracture toughness confirms the aluminum 7075 is brittle at $4.2 \mathrm{~K}$, the test results indicate that the difference of the material properties is not decisive to cause the fracture.

The other non-conforming factor is the actual radii of the corners on the end-shell. The measured radii of those corners in the broken shell are barely. It is well known that, within the 

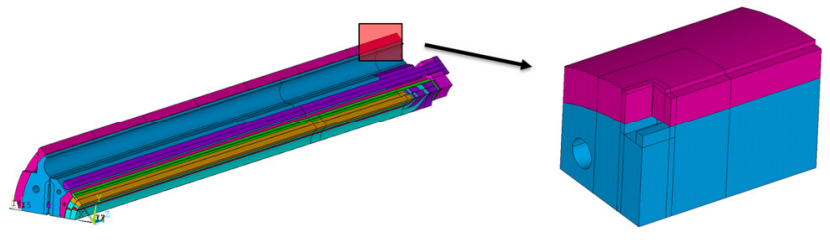

Fig. 5 Sub-model for the MQXFA shell analyses

context of linear elasticity theory, a power law singularity of stress exists at the apex of $90^{\circ}$ edge, and failure can occur when the local plastic zone initiated a flaw that exceeds the critical flaw size under a given load condition [5].

\section{Plastic ANALYSIS FOR THE CURRENT SHELl DESIGN}

To analyze the sharp corner impacts, elastoplastic analyses have been performed with a detailed 3D sub-model that includes weld block cut-out of the shell (Fig. 5). The analysis is under the graded framework described in [5], which is tailored to the general design process that has been successfully used to date for other MQXF magnets. The concept is to use a consecutively more advanced and detailed analysis as the component and load case are found to result in reduced margin with respect to relevant mechanical figures of merit.

The sub-model for this analysis is based on the general global 3D ANSYS model described in [8]. The global model applies the azimuthal interference of $750 \mu \mathrm{m}$, as defined for MQXFAP2 prototype magnet and the axial preload is provided by pre-tensioning $580 \mu \varepsilon$ on the stainless steel axial rods. The material plastic properties are based on the measured yield stresses and elongations at room temperature and $4.2 \mathrm{~K}$.

As pointed out above, the sharp corners represent stress concentrations. Numerically, an elastoplastic finite element analysis calculates strain and stress based on the local element size. As a consequence, increasing mesh refinement serves to increase the total stress without limit due to infinite elastic stress, however, the plastic strain and plastic deformation zone (PDZ) should converge with reduction of mesh size.

Fig. 6 shows the convergence analysis with different mesh sizes in order to ensure that the mesh is accurate enough to evaluate the solution on the small corner: the minimum element size is determined after which results variations are marginal --- the maximum plastic strain but also total plastic

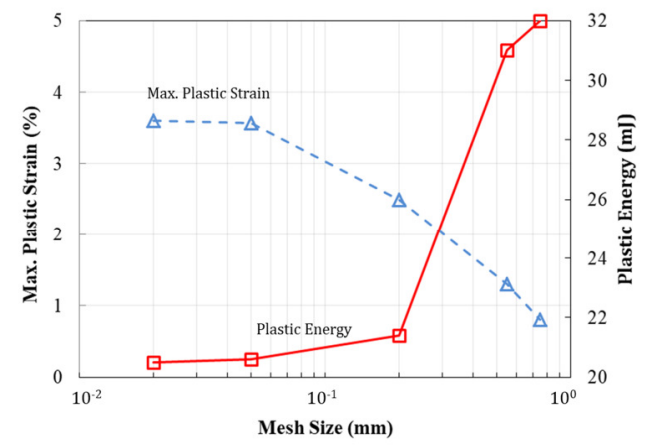

Fig. 6 Convergence study for the mesh size for $0.2 \mathrm{~mm}$ radii corner

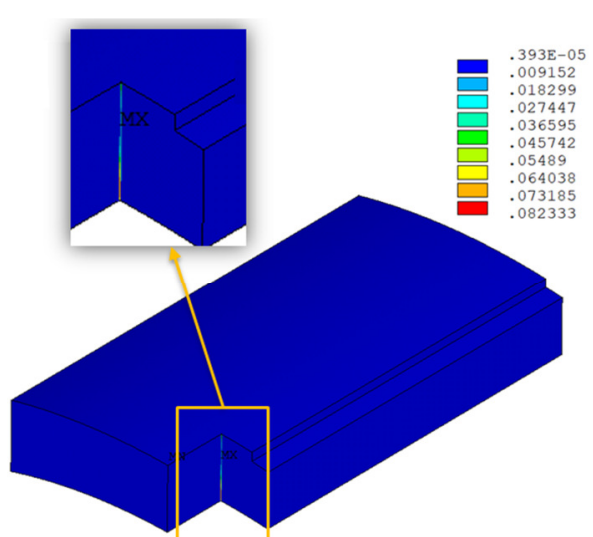

Fig. 7 Total mechanical strain (elastic + plastic) of the end shell at $1.9 \mathrm{~K}$ for the case of $0.1 \mathrm{~mm}$ radii

energy is no further accumulation of strain round the corner. In this analysis, the ratio of corner radius and the minimum mesh size is determined about 5 (5 elements at the apex). As the radius becomes smaller, smaller elements are required to obtain a converged solution.

The total strain (elastic + plastic) at the corner of $0.1 \mathrm{~mm}$ radius is about $8 \%$. Total strain is mostly azimuthal. The averaged measured elongations of Al 7075-T6 and T652 are $4.4 \%$ and $6 \%$, respectively. Please note that the FE solution is not valid as soon as the computed elongation exceeded the measured results. It's not conclusive that a crack was formed by the loads, but the fact that plastic deformation was formed with small radii under the load level of MQXFAP2 at $4.2 \mathrm{~K}$.

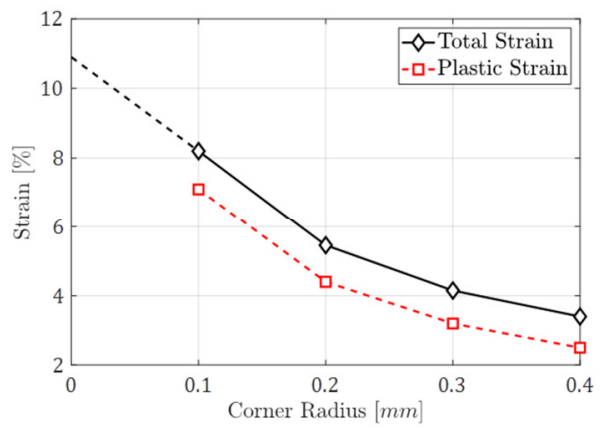

Fig. 8 Strain as a function corner radius

Since the tremendous computation cost with sharp corner in the finite element model, we only performed the cases of corner radii to the lowest radius of $0.1 \mathrm{~mm}$. Fig. 8 shows the functions of strain with different corner radii. The total strain is at least $11 \%$ at a pure sharp corner with a simple extrapolation. This analysis suggests that a round with $0.2 \mathrm{~mm}$ radius would cause local plastic failure.

According to the assumption of Linear Elastic Fracture Mechanism (LEFM), a crack could be initiated by a local plastic zone. As seen in Fig. 9, the plastic zone depth is nearly linear to the load level of the shells (Fig. 9, top); and is insensitive to corner radii for the cases with corner radius larger than $0.2 \mathrm{~mm}$ (Fig. 9, bottom). This indicates that the plastic deformation caused by a small corner is majorly dependent on the magnet preload level; the PDZ can be reduced significantly by lowering the pre-load applied on the 

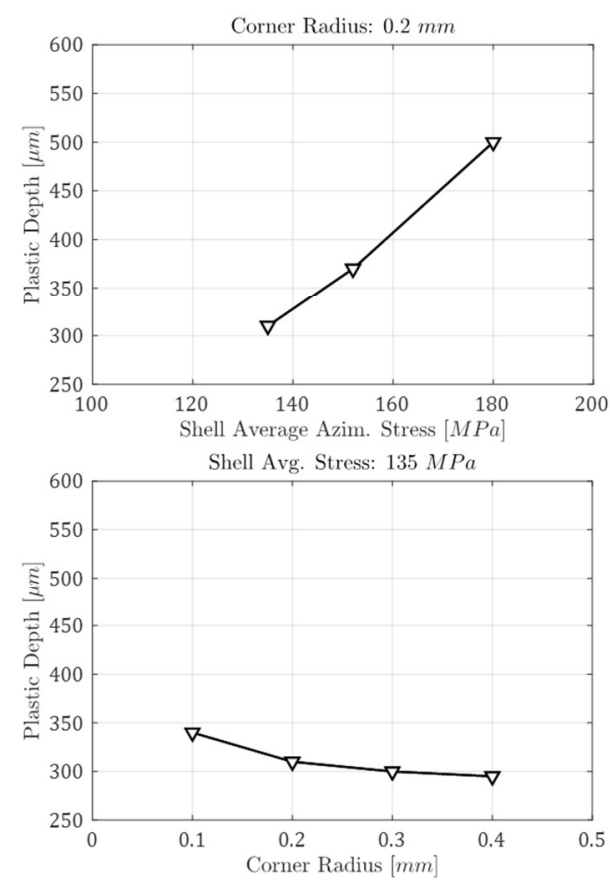

Fig. 9 Plastic depth as functions of shell average stress (top) and corner radius (bottom)

shell at room temperature.

\section{FRACTURE ANALYSES FOR THE Fractured SHELL}

Failure analysis for MQXFAP2 structure was performed by referencing ASME FFS-1 (Fitness-for-Service) [9] as a standard to accept use of nominally "brittle" materials with assumed flaws. The analysis relies on the R6 Failure Assessment Diagram (FAD) [10], which captures failure by LEFM, and plastic collapse simultaneously. The FAD is simply the formula:

$$
\begin{gathered}
K_{r}\left(S_{r}\right)=S_{r}\left[\frac{8}{\pi^{2}} \log \left(\sec \left(\frac{\pi}{2} S_{r}\right)\right)\right]^{-1 / 2} \\
S_{r}=\sigma / \sigma_{y}
\end{gathered}
$$

where, $\sigma_{y}$ is the yield stress at $4.2 \mathrm{~K}$. The FAD curve fits failure points and the corresponding stress at the axis (fracture and plastic failure), any work points inside the curve are considered safe.

As described in [6], part-through semi-elliptical surface flaw geometry was assumed to be the initial flaw size and this geometry may eventually grow to semi-circular flaw during operations. The major process is to determine the applied stress intensity $K_{I}$. For part-through cracks subject to primary stresses, $K_{I}$ can be written in the following form [7]:

$$
\begin{gathered}
K_{I}=F \sigma(x) \sqrt{\frac{\pi a}{Q}} \\
F \sigma(x)=\sum_{i=0}^{3} G_{i} A_{i} x^{i}
\end{gathered}
$$

where, $Q$ is the flaw shape parameter, which is a function of the ratio $a / c, a$ and $c$ are the minor and major elliptical radius of a crack. $F$ is a geometric constant that can be obtained from FEA model or published data. $\sigma(x)$ can be approximated as a cubic expansion of a total stress profile extracted from an unflawed FEA solution in the direction of assumed crack propagation through part thickness $x=a$ direction. $G_{i}$ is an influence coefficient for a part-through internal flaw in a cylinder; $A_{i}$ is the curve-fitting coefficient of the stress profile along the path of assumed crack propagation.

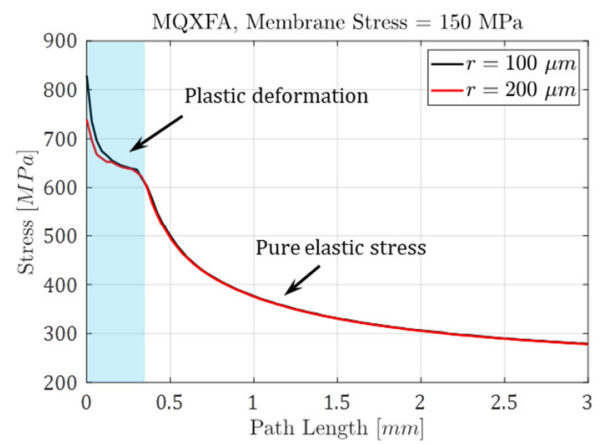

Fig. 10 Von Mises stress profiles along the crack direction with different corner radii of the weld block cut-out at $4.2 \mathrm{~K}$

Plots in Fig. 10 are the total Von Mises stress profiles of the cases of $0.1 \mathrm{~mm}$ and $0.2 \mathrm{~mm}$ corner radii from the sub-model. We don't have solution for $0.25 \mathrm{~mm}$ radius because of tremendous computation time. However, the solution does not seem to change drastically with the radius.

With the total Von Mises stress abstracted from the FEA solutions and a given crack length, the load point of each case can be determined in the FAD, as shown in Fig. 11. According to the fracture toughness measurements, the $K_{I C}$ used in the FAD calculation is $24 \mathrm{MPa} \cdot \sqrt{\mathrm{m}}$ in the C-L direction. Since the stress profiles of $0.2 \mathrm{~mm}$ and $0.1 \mathrm{~mm}$ corner radii are very close, Fig .11 only shows the load points for $0.2 \mathrm{~mm}$ corner radius.

As illustrated in Fig. 11, the critical flaw size of the case of $0.2 \mathrm{~mm}$ corner radius is $1 \mathrm{~mm}$ at $4.2 \mathrm{~K}$. Similarly, the critical flaw sizes are $2 \mathrm{~mm}$ for the case of $5 \mathrm{~mm}$ fillet. It's expected smaller critical flaw size with smaller corner radius, and it may be indicative that the PDZ size of the weld block cut-out of the MQXFAP2 end shell is close to the critical flaw size with a real corner radius on the level of $0.02 \mathrm{~mm}$.

Each load point determines a load line by connecting the

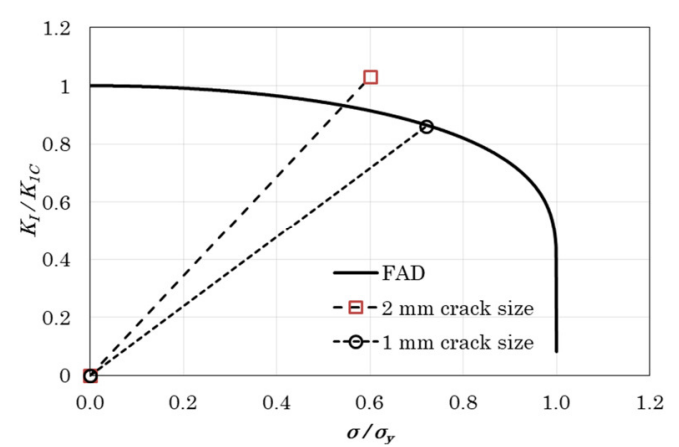

Fig. $11 \mathrm{FAD}$ for a $2 \mathrm{~mm}$ thumbnail crack initiated from the corner $(0.2 \mathrm{~mm})$ of the weld block of the MQXFAP2 end shell $\left(\sigma_{y}\right.$ is the yield stress of $635 \mathrm{MPa}$ ). 
origin. The load factor $\gamma_{L F}$ in the plot is defined as:

$$
\gamma_{L F}=\frac{L}{L^{\prime}}
$$

where, $L$ is the length from the original point to the load point; $L^{\prime}$ is the length from the original point to the projected load point, which is the intersection of load line and the FAD curve. Load factor is reserved for assessment against plastic failure criteria for the net section in an un-flawed structure. For MQXFA magnets, a flaw with a load factor of 1.2 is deemed acceptable for normal operations. It's apparently that the weld block cut-out of the MQXFAP2 end shell does not meet the load factor requirement.

Since the above FEA solutions don't provide the results of sharp corner, an analytical calculation was performed thereafter. The area of the fractured cut-out could be treated as a notched plate under in-plane load normal to the crack.

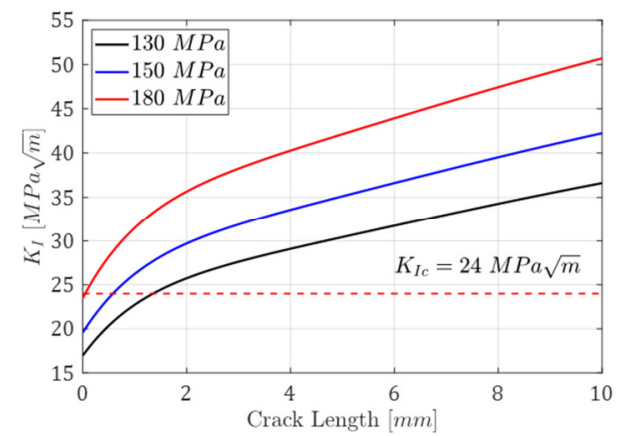

Fig. 12 The general stress intensity factor KI as function of crack size for a sharp corner.

Then the stress intensity factor $K$ is a function of crack length $a$ [11]:

$$
K_{I}=\sigma \sqrt{\pi a} F_{I}(a)
$$

where, $\sigma$ is the in-plane load, which is the shell membrane stress in our case. Fig. 12 shows $K_{I}$ as a function of crack size under different shell loads. For the measured average $K_{I C}$ of $24 \mathrm{MPa} \cdot \sqrt{\mathrm{m}}$, a notched cut-out under $180 \mathrm{MPa}$ membrane stress will fail. For MQXFAP2 shell stress of $150 \mathrm{MPa}$, a crack length larger than $0.6 \mathrm{~mm}$ will fail.

\section{Mitigation MEASURES FOR THE SHELlS}

\section{A. Shell cut-out modifications}

As displayed in Fig. 1, there three types of cur-out: alignment cut-out (Triangle cut-out), weld block cut-out, and weld strip cut-out. These geometric cut-outs on shell are designed for certain functions; and as analyzed above, the redesign of the cut-outs of the shells has to lower the stress concentration and satisfy the requirement of load factor of 1.2.

According to the subsequent analyses, large fillets allow the cut-out function their purposes; but also result in stress concentrations well within linear elastic behavior and well within the FAD. As illustrated in Fig. 13, different sizes fillets are applied on all the cut-outs and also removed some materials for the weld strip cut-out which cannot accommodate fillets larger than $0.5 \mathrm{~mm}$

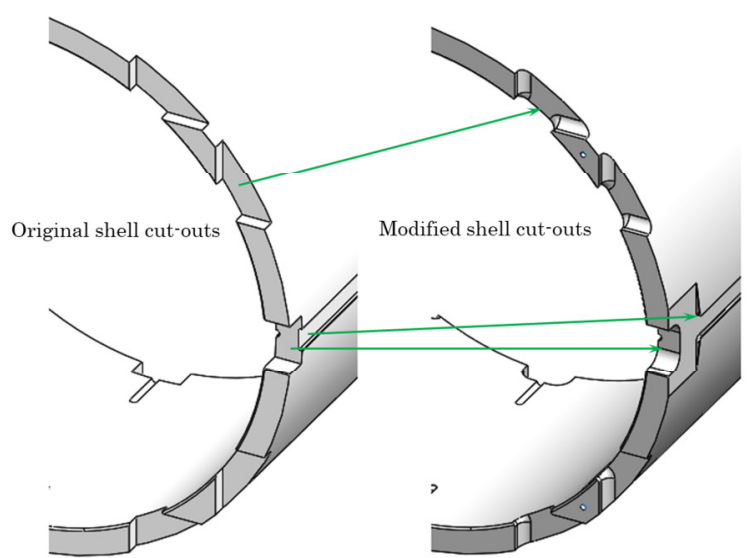

Fig. 13 Shell cut-outs have been re-designed to reduce the local stress concentration.

the triangle cut-out will need at least $5 \mathrm{~mm}$ fillet to have a load factor larger than 1 [5]. We analyzed larger fillets for the triangle cut-out, and eventually selected $10 \mathrm{~mm}$ root fillet. Similarly, the weld block cut-out requires even larger fillets. As analyzed with different fillet sizes, a fillet of $15 \mathrm{~mm}$ is applied.

Since the weld trip cut-out requires cannot accommodate any fillets larger than $0.5 \mathrm{~mm}$, the material of the stress concentration was removed. This offers significant reduction on the stress around the corners.

\section{B. Preload operation modifications}

Since the shell membrane stress (shell load level) plays a big role in the stress concentration, reducing shell stress is another measure to mitigate the stress concentration and plastic deformation around the corner.

There are two major ways to adjust the shell loads in MQXFA magnets: (a) azimuthal shimming; (b) G11 pole key gaps with the collars. Azimuthal shimming provides the main loads of the coils by tensioning the shells; while pole keys control the fraction of the shell forces transferred to the coil by engaging to the collars. For a given azimuthal shimming, one can finely regulate the interception ratio to get different coil loads with different pole key gaps.

In order to reduce the shell stress but maintain a similar coil load, a larger pole key gap is required. Ultimately, one can choose a gap that pole keys are never engaged. In this case,

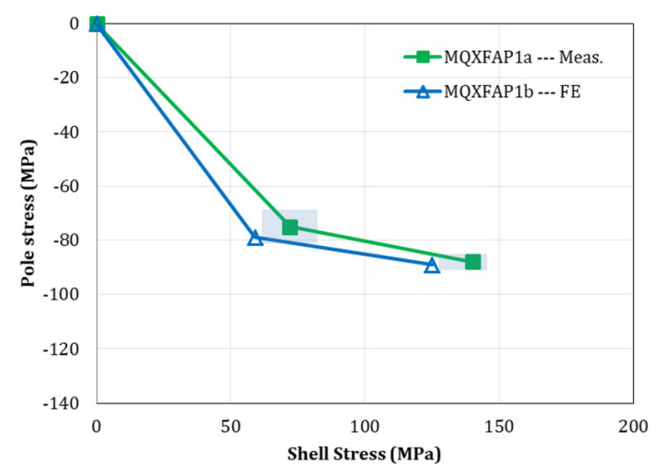

Fig. 14 Transfer function of MQXFAP1b compared with MQXFAP2. 
the shell stress is $100 \%$ transferred to the coil, which means we will have the largest shell stress reduction for a desired coil load.

As a lesson learned from MQXFAP2, we set larger pole key gaps ( 3 mil per key side) for the future magnet MQXFAP1b. As shown in Fig. 14, the shell stress of MQXFAP1b is 130 $\mathrm{MPa}$, which is about $22 \mathrm{MPa}$ lower than that of MQXFAP2.
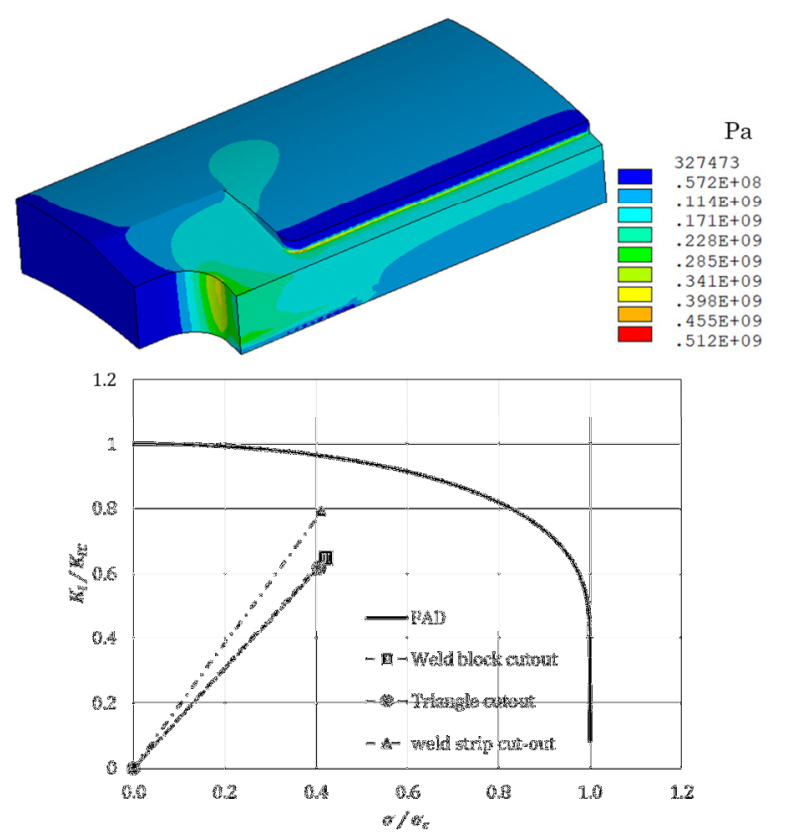

Fig. 15 Von Mises stress distribution on the sub-model of the weld block cut-out (top); and FAD load points for a $2 \mathrm{~mm}$ thumbnail crack in the three types of cut-outs with the updated features and new shell stress of 130 MPa (bottom).

Fig. 15 top shows the Von Mises stress with new cut-out features and reduced shell stress. There is no plastic deformation formed in the structure. The peak stress is about $512 \mathrm{MPa}$ around the corner of the weld strip cut-out; stress in the weld block cut-out is well below $400 \mathrm{MPa}$.

TABLE III

LOAD FACTORS OF THE CUT-OUTS OF THE MQXFAP1B END-SHELL

\begin{tabular}{lll}
\hline \hline Cut-out & Fillet radius $(\mathrm{mm})$ & Load factor for 2 mm crack \\
\hline Triangle cut-out & 10 & 1.46 \\
Weld block cut-out & 15 & 1.43 \\
Weld strip cut-out & $\begin{array}{l}0.5 \text { with removed } \\
\text { material on the high } \\
\text { stress area }\end{array}$ & 1.24 \\
\hline \hline
\end{tabular}

Fig. 15 bottom shows the FAD of the MQXFAP1b end shell cut-outs. The fracture analyses with the above two enhancement measures show that the MQXFAP1b shells with the new designs are well within the FAD. The $K_{I C}$ used for the analyses is $24 \mathrm{MPa} \cdot \sqrt{\mathrm{m}}$. Please note, the $K_{I C}$ used for the triangle cut-out and the weld block cut-out is in C-L direction; the $K_{I C}$ used for the weld strip cut-out is in C-R direction because of an assumed outside surface crack. The corresponding load factors are listed in Table III.

\section{Ultrasonic Inspection Specification for the Shells}

The analyses reveal the critical flaw size is $2 \mathrm{~mm}$ for $5 \mathrm{~mm}$ fillet corner of the MQXFA end-shell, which requires a Class
AA ultrasonic inspection to detect. The critical flaw size will be slightly larger than $2 \mathrm{~mm}$ for $10 \mathrm{~mm}$ fillet. As a result, the analyses assume that a $2 \mathrm{~mm}$ crack initiates at the area of stress concentration.

Detection limits for ultrasonic methods in wrought aluminum (and most other standards) are calibrated to circular flaws based on grade, described in ASTM B594-13 [12]. The calibration flaws for inspection class are shown in Table IV.

TABLE IV

FLAW SIZES CORRELATED TO INSPECTION GRADES FOR ALUMINUM FORGINGS

\begin{tabular}{lll}
\hline \hline Inspection Class & Calibration Block & Allowable Critical Flaw Size \\
\hline AAA & $0.40 \mathrm{~mm}$ & $>0.90 \mathrm{~mm}$ \\
AA & $0.79 \mathrm{~mm}$ & $>1.77 \mathrm{~mm}$ \\
A & $1.19 \mathrm{~mm}$ & $>2.67 \mathrm{~mm}$ \\
B & $1.98 \mathrm{~mm}$ & $>4.44 \mathrm{~mm}$ \\
\hline \hline
\end{tabular}

For a flaw of $2 \mathrm{~mm}$, an inspection Class of "AA" is required; a higher Class of "AAA" is required if a flaw smaller than $1.77 \mathrm{~mm}$ must be detected. For Class A inspection, the detectable flaw size is about $3 \mathrm{~mm}$. Components which do not pass inspection will either be rejected, or quarantined for further examination.

TABLE $V$ lists the load factors of cut-outs of the MQXFAP1b end-shell with Class $\mathrm{A}$ and AA inspections. Class A inspection cannot satisfy the load factor requirement of the weld strip cut-out of the end-shell. From Class A to Class AA does not cost very differently. Therefore, Class AA has been specified for MQXFA magnets to the shell vendors, and documented officially.

TABLE V

LOAD FACTORS OF THE END-SHELL CUT-OUTS WITH CLASS A AND AA INSPECTION

\begin{tabular}{llll}
\hline \hline & Triangle cut & Weld block cut & Weld strip cut \\
\hline Class AA & 1.4 & 1.4 & 1.24 \\
\hline Class A & 1.5 & 1.7 & 1.16 \\
\hline \hline
\end{tabular}

\section{CONCLUSION}

MQXFAP2 has severe fracture failure on the end shell due to small corner radii. The fracture occurred after cool-down to $4.2 \mathrm{~K}$. According to the plastic analysis, the cut-out area of the fractured shell has high stress concentration that exceeds the plastic limit locally at cold. As a result, the calculated load point is outside the margin defined in the Structural Design Criteria.

Fracture analyses suggest that adding large fillets on the cut-out corners of the shells will reduce the stress concentration and also release the elastic energy if a local flaw is present; Reduce the shell preload is also considered as another mitigation measure to lower the local stress. The final modifications are: a $10 \mathrm{~mm}$ fillet applied on the triangle cutout, $15 \mathrm{~mm}$ fillets applied on the weld block cut-out, and 0.5 $\mathrm{mm}$ fillet applied on the weld strip cut-out, but also remove the materials around the stress concentration area.

Based on the fracture assessments with the updated cut-out features, the new shell designs are well within FAD with load factors larger than 1.2. 


\section{ACKNOWLEDGMENT}

The authors would like to thank warmly Thomas Johnson, Ahmet Pekedis, James Swanson, Joshua Herrera and Matthew Reynolds for their dedicated work and enthusiasm on this project; thank Bob Walsh at National High Magnetic Field Laboratory (NHMFL) to provide the fracture toughness test results.

\section{REFERENCES}

[1] P. Ferracin, et al, "Development of MQXF: The Nb3Sn Low- $\beta$ Quadrupole for the HiLumi LHC," IEEE Trans. Appl. Supercond., vol. 26, pp.4000207, June 2016.

[2] H. Pan et al., "Assembly tests of the first $\mathrm{Nb}_{3} \mathrm{Sn}$ low-beta quadrupole short model for the Hi-Lumi LHC upgrade," IEEE Trans. Appl. Supercond., vol. 26, pp. 4001705, Jun. 2016.

[3] P. Ferracin, et al, "The HL-LHC Low- $\beta$ Quadrupole Magnet MQXF: from Short Models to Long Prototypes," IEEE Trans. Appl. Supercond., vol. 29, pp.4001309, June 2019.

[4] G. Ambrosio, et al, "Nb3Sn High Field Magnets for the High Luminosity LHC Upgrade Project," IEEE Trans. Appl. Supercond., vol. 25, pp.4002107, June 2015.

[5] H. Pan et al., "Failure Assessments for MQXF Magnet Support Structure with a Graded Approach," IEEE Trans. Appl. Supercond., vol. 29, pp. 8401507, Jun. 2019.

[6] S. Prestemon, E. Anderssen, "US HL-LHC Accelerator Upgrade Project Structural Design Criteria". US-HILUMI-DOC-909. 2018.

[7] T. Anderson, "Fracture Mechanics", 2nd Edition, p369-320, 1994.

[8] H. Pan et al., "Mechanical Design Studies of the MQXF Long Model Quadrupole for the HiLumi," IEEE Trans. Appl. Supercond., vol. 27, pp. 4004105, June. 2017.

[9] ASME Standards Collection - ASME API 579-1/ASME FFS-1, 2016.

[10] British Energy Generation Limited, "Assessment of the Integrity of Structures Containing Defects", 699 R6 Revision 4, Amendment 7, April 2009.

[11] H. Tada, et al, "The Stress Analysis of Cracks Handbook", $3^{\text {rd }}$ Edition, 2000.

[12] ASTM B594 "Standard Practice for Ultrasonic Inspection of AluminumAlloy Wrought Products", 2013 